\title{
Estimates of Shark Species Composition and Numbers Associated with the Shark Fin Trade Based on Hong Kong Auction Data
}

\author{
Shelley C. Clarke, Murdoch K. McAllister and Catherine G. J. Michielsens \\ Renewable Resources Assessment Group, Department of Environmental Science and Technology \\ Imperial College London, South Kensington SW7 2AZ, United Kingdom
}

Clarke, S. C., M. K. McAllister, and C. G. J. Michielsens. 2005. Estimates of Shark Species Composition and Numbers Associated with the Shark Fin Trade Based on Hong Kong Auction Data. J. Northw. Atl. Fish. Sci., 35: 453-465. doi:10.2960/J.v36.m488

\begin{abstract}
The species composition and number of sharks used by the shark fin trade were estimated from a partial set of daily auction records for the world's largest shark fin trading centre in Hong Kong for the period October 1999 to March 2001. More than 10000 lot descriptions of shark type, fin position, fin size and fin weight were translated and statistically modeled using Bayesian Markov Chain Monte Carlo methods (WinBUGS). These methods allowed a robust estimation of missing information in individual auction records, as well as of entire auctions for which no data are available, through a hierarchical model with uninformative priors. The model provides estimates of the complete data set for the sampled period, including the total auctioned weights of fins by shark type and fin position. Separate studies, undertaken in Hong Kong to genetically map trade names to species names, are being used to align the estimates with particular taxa. This paper demonstrates how the traded quantity estimates can be converted to the weight and number of sharks represented based on preliminary conversion factors from the literature and from this research. A potentially more robust Bayesian conversion algorithm, involving fin size-classes and stochastic relationships between fin lengths and fin weights, is outlined for future implementation.
\end{abstract}

Key words: Hong Kong, modeling, shark fin, sharks, trade.

\section{Introduction}

Much of the current concern regarding the sustainable use of shark resources centres on the practice of finning and the role of the shark fin trade in driving shark mortality. A detailed case study analysis could be undertaken of the many variables determining whether sharks are targeted and finned in particular fisheries (e.g. McCoy and Ishihara, 1999). However, available market data can be used cost-effectively to assess the numbers of sharks represented by traded quantities of shark fin, and to identify the species composition in trade. Given the absence of extensive and reliable species-specific shark catch statistics, estimates of shark landed weights or numbers generated from fin trade-based studies can also provide useful reference points against which to evaluate reported shark catch rates. In these ways, shark fin market data can contribute to a better understanding of shark utilization rates and provide useful insights into the current pressures facing world shark populations. Similar methods, once proven, can also be applied to other marine or wildlife species of concern.

Hong Kong, which serves as an entrepôt for Mainland China, has been the centre of the world trade in shark fins for many decades (Kreuzer and Ahmed, 1978; Parry-
Jones, 1996; Vannuccini, MS 1999; Fong and Anderson, 2002). Estimates of Hong Kong's share of the trade have varied between $50 \%$ and $85 \%$ ((Tanaka, 1994) (based on 1990 data); Vannuccini, MS 1999 (based on 1992 data); Clarke, MS 2002 (based on 2000 data)). In recent years, unprocessed shark fins have been exported to Hong Kong by at least 85 countries on six continents (Clarke and Mosqueira, 2002). Even when a recent trend towards importing more shark fins in frozen form is accounted for, the weight of imports into Hong Kong has increased year-on-year at a rate of 5\% (Clarke, MS 2002). Rather than relying on customs statistics, this study is based on records from daily shark fin auctions held in Hong Kong by approximately 16 different trading houses. A proportion of fins imported to Hong Kong in unprocessed form are auctioned by importers to processors, who generally re-export the fins to Mainland China for low-cost processing. Data collection at this point in the supply chain allows fins to be characterized by shark type, fin position, and fin size. Since this market draws large quantities of shark fins from all over the world, detailed characterization of this market can be extrapolated, with appropriate caveats, to depict the global trade.

This paper describes a probabilistic (Bayesian) approach to modeling shark fin auction data and 
demonstrates how these can be used to derive estimates of total traded fin weights and shark numbers. Although Bayesian statistics are computationally more demanding than frequentist analogs, their use in fishery stock assessment is steadily gaining momentum (Punt and Hilborn, 1997; McAllister and Kirkwood, 1998; McAllister et al., 2001). Bayesian methods allow parameters to be treated as random variables rather than as fixed values and thus explicitly account for uncertainty in the statistical modeling, as well as provide a more intuitively obvious interpretation of resulting probabilities. This application of probabilistic statistics involves prediction and filling of missing trade data, resulting in more reliable estimates and probability intervals.

\section{Materials and Methods}

Shark fins auctioned in Hong Kong are organized into lots, which are described on sheets distributed to all participating bidders. Each sheet lists the name of the trading house, the date, a description of the fin (by trade name of which some are loosely species-specific, and by fin size and position), and the number of bags in each lot. These records are usually annotated after the auction by official record keepers to show the weight and official selling price of each lot. Because the records do not pro- vide information about the source location of the fins, it is not possible to draw any conclusions about the country or ocean of origin from these records. Sheets from 148 auctions were obtained spanning the period from October 1999 to February 2001, representing a subset of all auctions held. Lot descriptions, weights and prices were translated and transcribed into an Excel database for all 10669 lots. In addition, a calendar showing the name of the trading houses holding auctions between October 1999 and March 2001 was compiled to identify missing auction records. During this period, 513 auctions were held, $\sim 29 \%$ of which was observed.

Statistical models were developed to address two important deficiencies in the data set. One model was for filling of missing lot weights for a small number of trading houses which refused to disclose this information (Model A). The other model was for filling of auctioned quantities on dates for which no records were available (Model B). The models were formulated using WinBUGS (Bayesian inference Using Gibbs Sampling) software, version 1.3 (http://www.mrc-bsu.cam.ac.uk/bugs) with a hierarchical modeling approach (Gelman et al., 1995). Once a complete data set was generated, the results were extrapolated to characterize the shark fin trade in Hong Kong as well as the global market (Fig. 1).

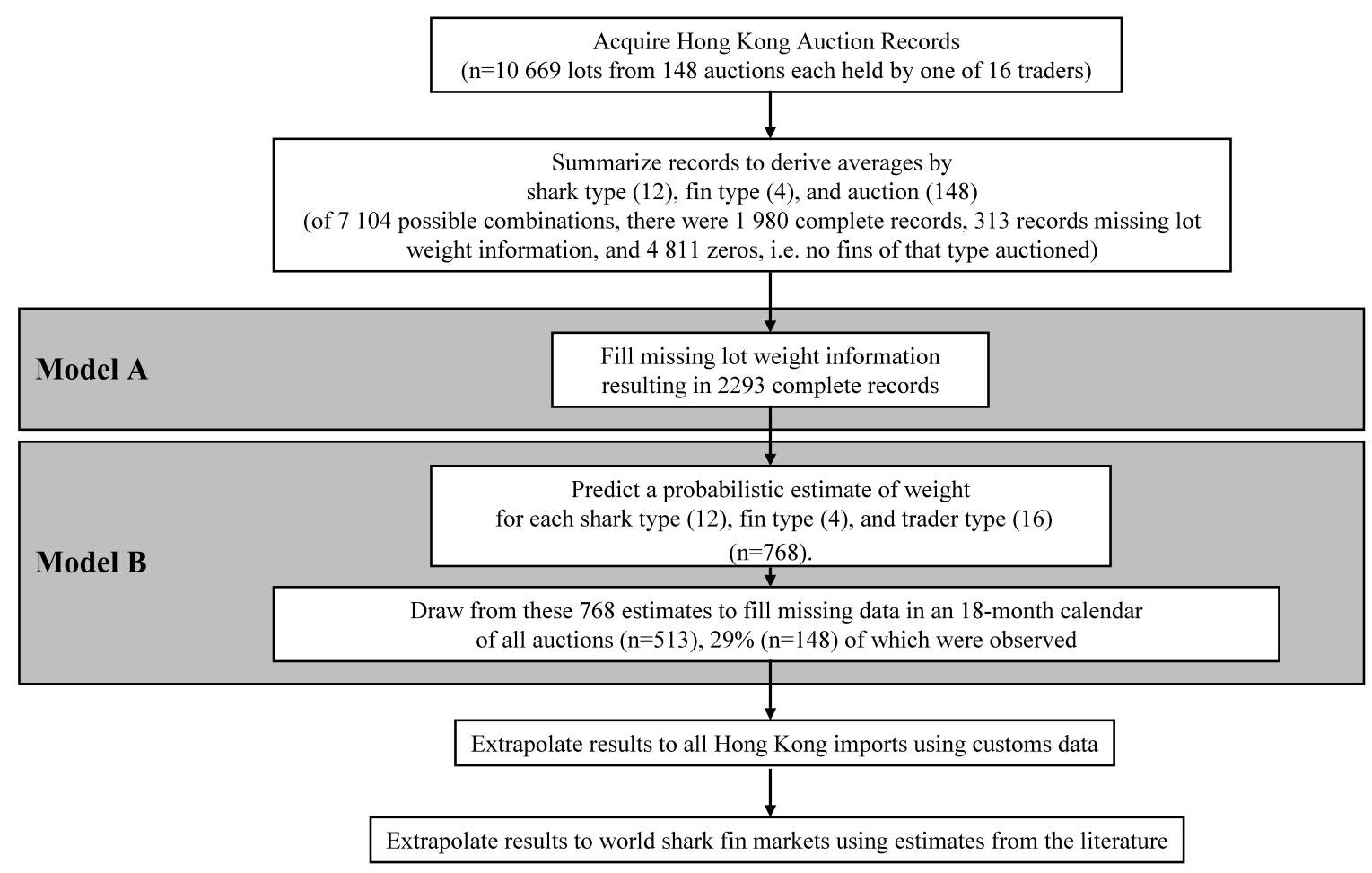

Fig. 1. Overview of the study methodology describing the available data, the use of Models A and B to fill in missing data, and the resulting extrapolation from the dataset to the global trade in shark fins. 
Although shark fin lots were described on the sheets using more than 50 different market categories for shark type, this analysis focused on eleven common categories plus one additional composite category for all other types. The eleven categories were chosen to complement a parallel study mapping these categories to particular species or genera using DNA polymerase chain reaction techniques (Shivji et al., 2002; Clarke, 2003). Trade category-taxonomic matches currently undergoing testing are shown in Table 1. Traders often record the fin position for each lot, particularly when the market value of the fins depends not only on the type of shark, but also on the body position of the fin. The three most commonly recorded fin positions are dorsal, pectoral, and lower caudal, but other fin positions, such as anal, upper caudal, and second dorsal, are also observed. In this analysis, only the three most common fin positions were modeled separately. All other fin positions, including large numbers of lots of unspecified fins, were grouped into an "other" category. No temporal trends in weights from observed auctions or in overall import records for Hong Kong were observed. Furthermore, seasonal supply patterns for particular species were not acknowledged by traders and were expected to be obscured both by the number of importing countries and the ability to stockpile dried fins at the point of origin (Clarke, MS 2002). For these reasons, seasonal effects were not considered important in the model.

The aim of Model A was to predict the lot weight for records that revealed only the number of bags in the lot. This involved using the relationship between the number of bags in the lot and the lot weight determined from those records where both data were disclosed. The data points used when estimating this relationship were the average number of bags and average lot weight for each combination of shark type and fin position for each
auction.All observations for which the average number of bags was zero (i.e. there were no fins of that particular combination auctioned) were removed to avoid biasing the relationship. Plots of these data indicated a linear equation of the form $y=m x+b$, where $y$ is the average lot weight and $x$ is the average number of bags in the lot, would be appropriate (Fig. 2). However, to account for potential differences in slope and intercept by shark type and fin position, the model was expanded to include additive effects for slope and intercept. The model took the form of mean weight $=(($ base slope + shark effect + fin effect $) \times$ mean number of bags) + (base intercept + shark effect + fin effect). To avoid negative weight values, all weight data were transformed by natural logarithm, the model was fitted to the transformed data, and all predicted weights were back-transformed. The overall slope and intercept as well as slope and intercept effects for each shark type and fin position were estimated using normally distributed uninformative (diffuse) priors (Fig. 3). The shark type and fin position effects were constrained to sum to zero. A normally distributed error term for the regression equation was also included, i.e., $y=m x+b+\varepsilon$ which accounts for the variance in mean lot weight.

The model estimates a base slope and intercept for all observed fins in aggregate as well as separate additive effects (or offsets) for each shark type and fin position individually. The shark type-specific and fin positionspecific slope and intercept were used to predict the average lot weight for that combination. In the final step, the average lot weight was multiplied by the observed number of lots of that combination in each auction to provide a total auction weight for the combination. The prior probability distributions (priors) are uninformative (diffuse). However, the data consist of 1980 pairs (average number of bags, average lot weight per auction) of points which exert a strong influence on the estimated slope and intercept parameters (posterior probability distributions or posteriors). Using an in-built capacity of the WinBUGS

TABLE 1. Hypothesized matches between trade names used in the Hong Kong shark fin market and scientific taxa. Detailed testing and verification of these matches is the subject of a parallel study (Shivji et al., 2002; Clarke, 2003).

\begin{tabular}{|c|c|}
\hline Trade name & Scientific name \\
\hline \multicolumn{2}{|c|}{ Ya Jian ................................................... Prionace glauca } \\
\hline \multicolumn{2}{|c|}{ Qing Lian .......................................................... Isurus oxyrinchus or I. paucus } \\
\hline \multicolumn{2}{|c|}{ Wu Yang .............................................................. Carcharhinus falciformis, C. galapagensis or C. albimarginatus } \\
\hline \multicolumn{2}{|c|}{ 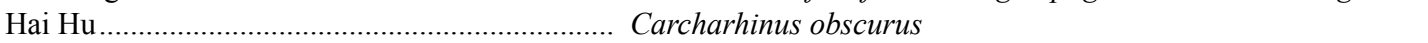 } \\
\hline \multicolumn{2}{|c|}{ Bai Qing .............................................................. Carcharhinus plumbeus } \\
\hline \multicolumn{2}{|c|}{ Ruan Sha .............................................................. Galeocerdo cuvier } \\
\hline \multicolumn{2}{|l|}{ Chun Chi ... } \\
\hline \multicolumn{2}{|c|}{ Gu Pian.......................................................... Sphyrna mokarran or Sphyrna sp. } \\
\hline \multicolumn{2}{|r|}{ Alopias sp. or Isurus paucus } \\
\hline \multicolumn{2}{|r|}{ Carcharhinus leucas or Carcharhinus amboinensis } \\
\hline Liu Qiu........ & .. Carcharhinus longimanus \\
\hline
\end{tabular}




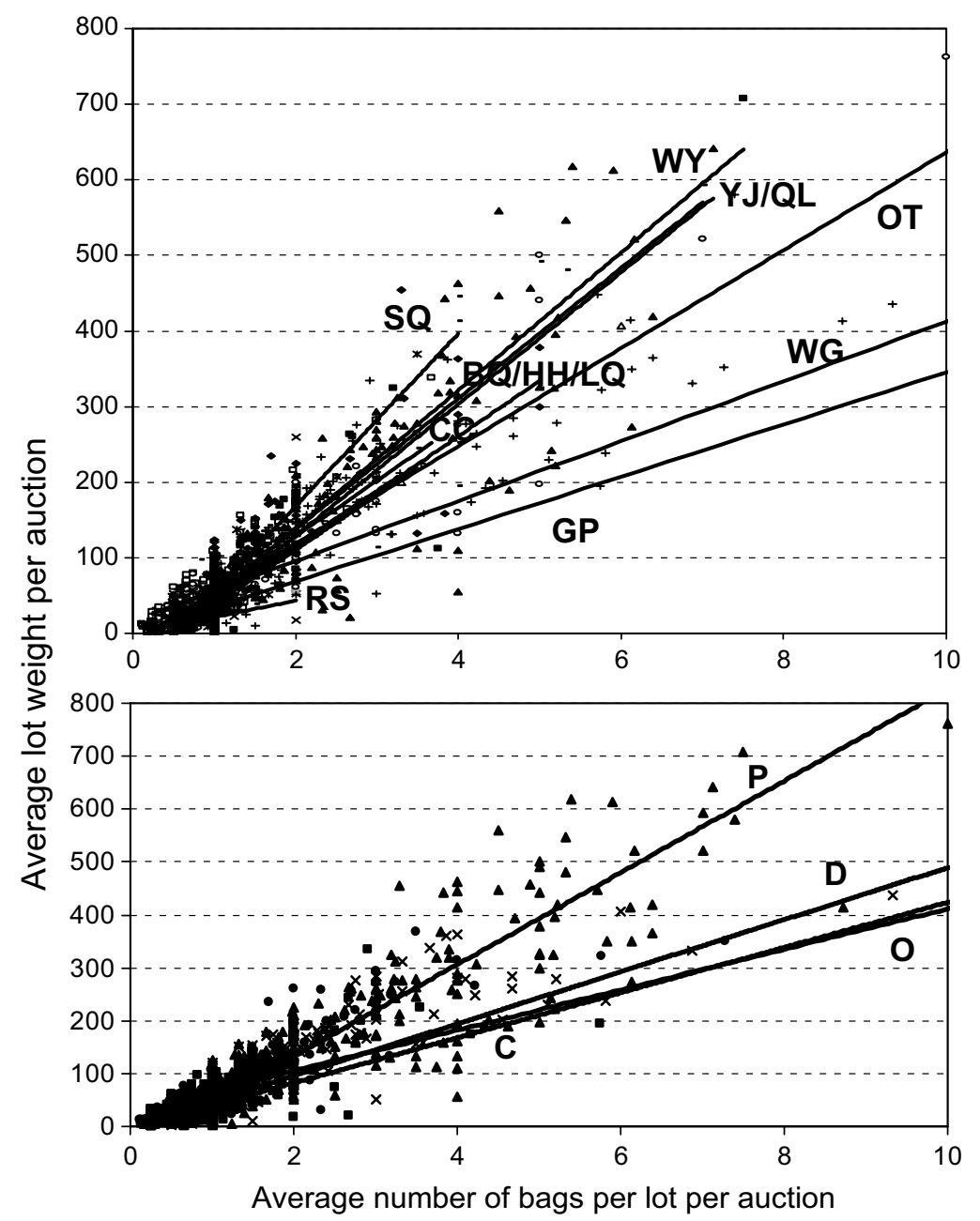

Fig. 2. Plot of average number of bags per lot per auction against average weight per lot per auction, by (A) shark type and (B) fin position. Although this study uses a Bayesian approach to determining the appropriate slopes and intercepts, maximum likelihood-based linear trend lines are used here to illustrate that slopes and intercepts vary by shark type and fin position. These effects should thus be treated as offsets from a base slope and intercept. Labels for shark type follow the Chinese trade names in parentheses: Ya Jian (YJ), Qing Lian (QL), Wu Yang (WY), Hai Hu (HH), Bai Qing (BQ), Ruan Sha (RS), Chun Chi (CC), Gu Pian (GP), Wu Gu (WG), Sha Qing (SQ), Liu Qiu (LQ), and other (OT) (see Table 1 for associated species names). Labels for fin position also follow in parentheses: dorsal (D), pectoral $(\mathrm{P})$, lower caudal $(\mathrm{C})$, and other $(\mathrm{O})$. Outliers have been removed for presentation only.

software for data filling, lot weights were predicted for 313 missing values. Although the numbers of missing data points filled by Model A is small relative to the number of complete records, these 313 values derive mainly from one of Hong Kong's largest traders. Therefore, the results of Model A allow complete records from this trader to be generated from data available from other traders, and provide a full set of traded weights for every observed auction. Model B was designed as a mixed binomialnegative binomial model using the traded weight for each shark type-fin position combination in each auction as the basis for predicting analogous traded weights in unobserved auctions. The mixed model conceptualization was motivated by plots of total auction weight by shark type-fin position combination, which showed a large spike of values at zero i.e. many instances in which no fins of a 


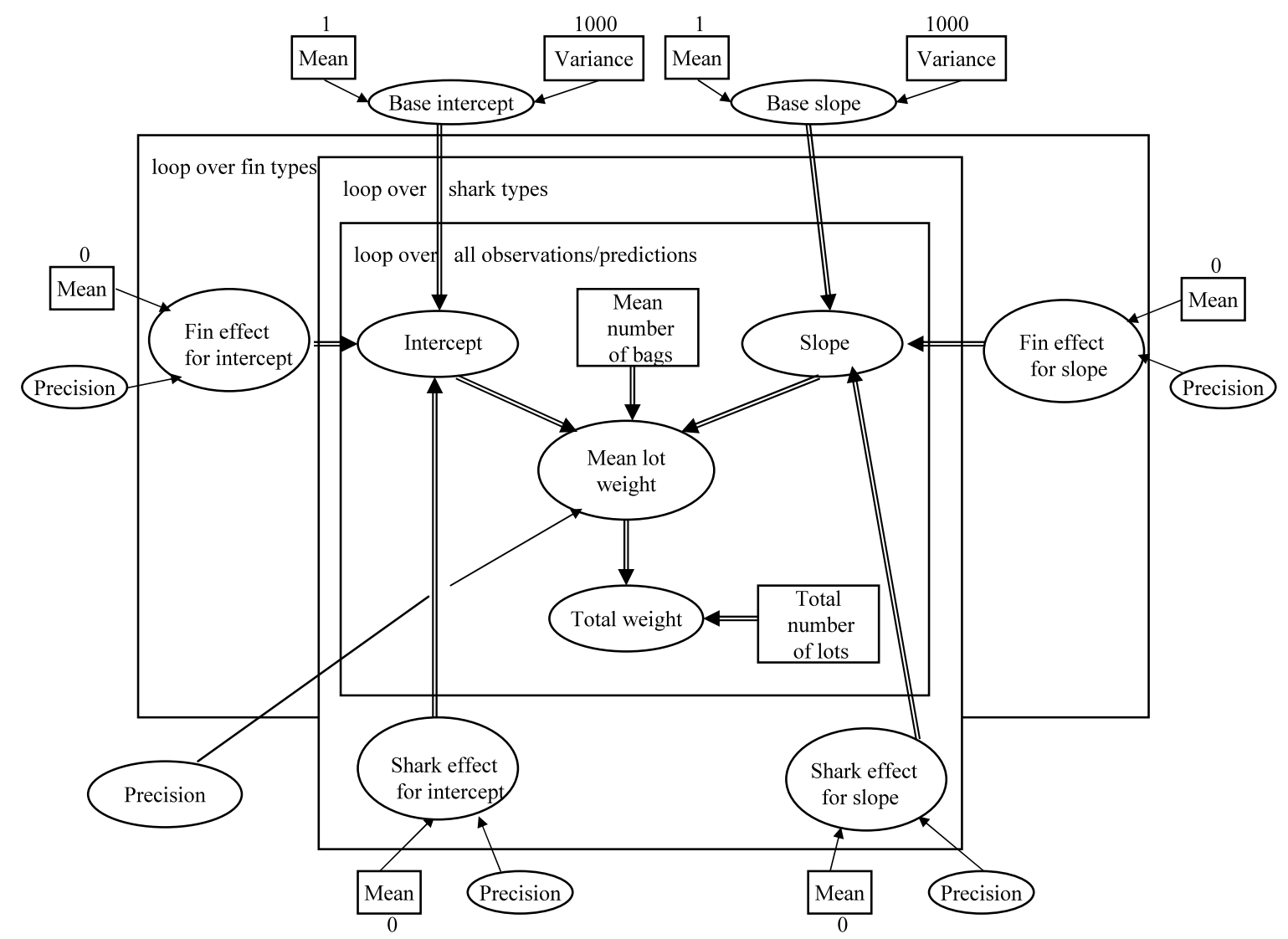

Fig. 3. Flowchart showing derivation and relationships between parameters for Model A. Large rectangular boxes represent loops. Thin arrows indicate that the 'parent' node determines the 'child' node in a stochastic manner. Bold arrows indicate that the 'child' node is logical and therefore calculated from the 'parent' node. Ovals represent stochastic nodes (random variables), whereas small rectangles represent deterministic nodes, such as data or fixed values for priors (values as shown). Priors for mean nodes (rectangles) were assumed normally distributed around zero (for effects) or one (for base slope and intercept). Priors for variance nodes (rectangles) were set at 1000 . All random variables for precision (1/variance) were determined using a gamma distribution with scale parameter 0.001 and shape parameter 0.001 ; these precision priors are not shown on the diagram for simplification purposes.

particular combination were auctioned, and a flattened distribution with a long tail of non-zero values representing observations where fins of the particular combination were auctioned with total weights varying over a wide range (Fig. 4). These data points were found to fit the negative binomial distribution (as given in Hilborn and Mangel, 1997) through chi squared testing $(0.975<P<0.99)$. The data also suggested that traded weights varied by trading house. Thus, it was decided to use the model to predict posterior distributions for the traded weight-per-auction for all combinations of shark type (12), fin position (4), and trader (16), i.e. 768 combinations in total.

The binomial portion of Model B estimates the probability of zero traded weight, using, as in Model A, a base parameter with additive effects for shark type, fin position, trader, and an additional shark type-fin position interaction term (Fig. 5). The interaction term is necessary in the binomial portion of the model only. This is because some sharks' fins vary considerably in value depending on fin position; thus, the fins are always sorted by fin position and never left unspecified. In contrast, when a particular shark's fins are all nearly equal in value, regardless of fin position, the fin position is frequently left unspecified, which results in a very low probability of observing a zero weight in the unspecified category. The negative binomial portion of Model B predicts the traded weight of fins when the traded weight is not zero. This portion of the model also uses base parameters and offsets for shark type, fin position, and trader effects. In each Monte Carlo iteration of the model, the product of the binomial parameter, (either 0 or 1 ) and the negative binomial parameter (a 

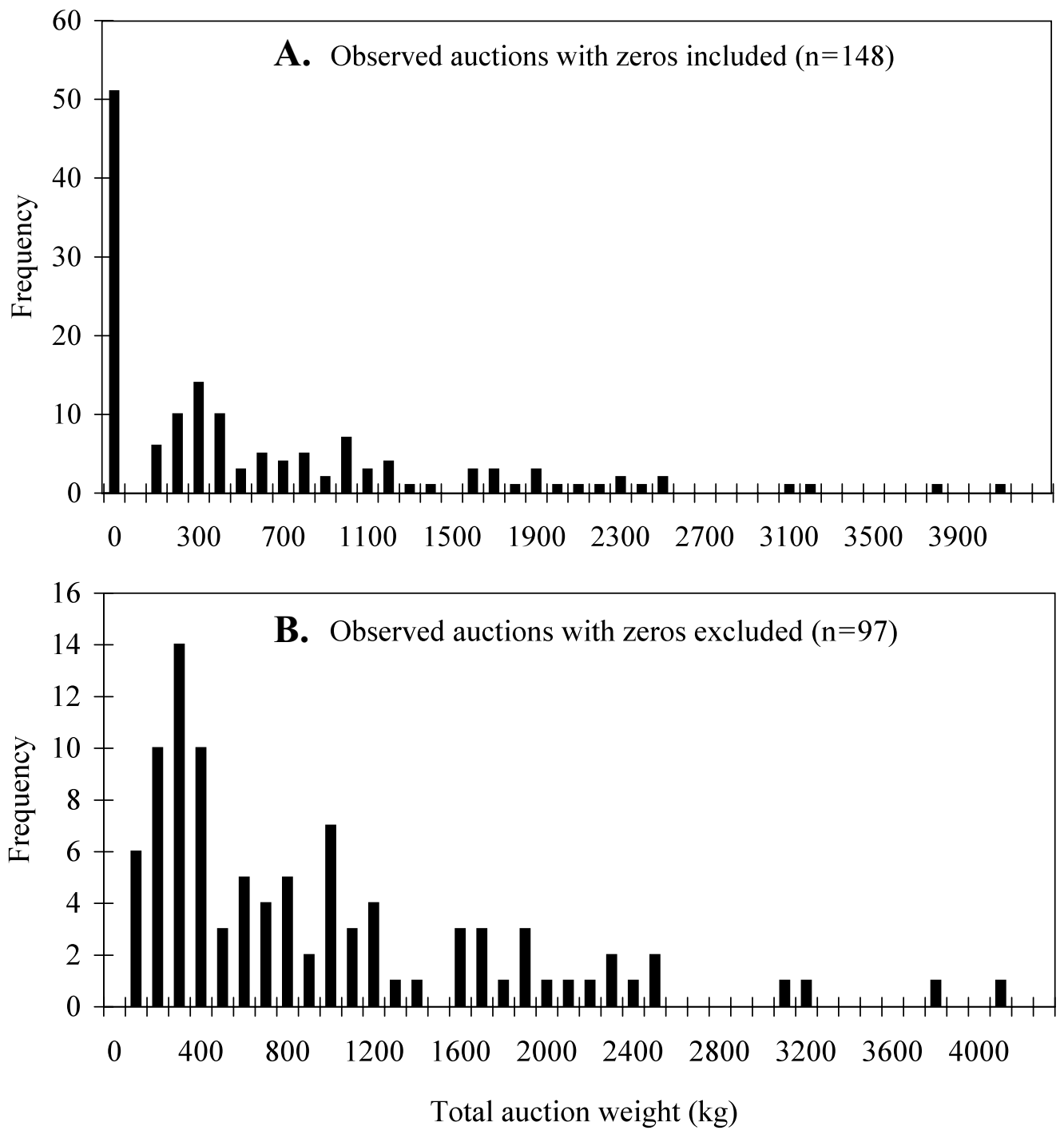

Fig. 4. Example histogram of data for a given shark type-fin position combination showing the observed distribution of total weight per auction for Ya Jian pectoral fins, (A) with zero observations included and (B) with zero observations excluded.

positive integer representing traded weight-per-auction) is calculated for each of the 768 combinations. A probability distribution is generated for each shark type-fin position combination.

The final step in Model B involves sampling from the distributions of the 768 combinations to fill in an array representing the auction calendar for the period from October 1999 to March 2001. The array consists of 48 shark type-fin position combinations in one dimension and a vector of the sequence in which trading houses held auctions in the other dimension (513 auctions in total). Each cell in the array can thus be either filled by an observed traded weight or mapped to one of the 768 distributions and iteratively sampled. Column totals produced through iteration provide total traded weights by shark type and fin position over the 18-month period of interest.

\section{Results}

The first step in using Model A was to simplify the 12 effects terms for shark type and the 4 effects terms for fin position. This step both improved the convergence efficiency of the model and increased the estimation power for those shark types with limited observations. To accomplish this, Model A was run using only shark type effects, probability intervals for each shark type effect were observed, and shark types were grouped based on similarities in the intervals. Similar model runs were 


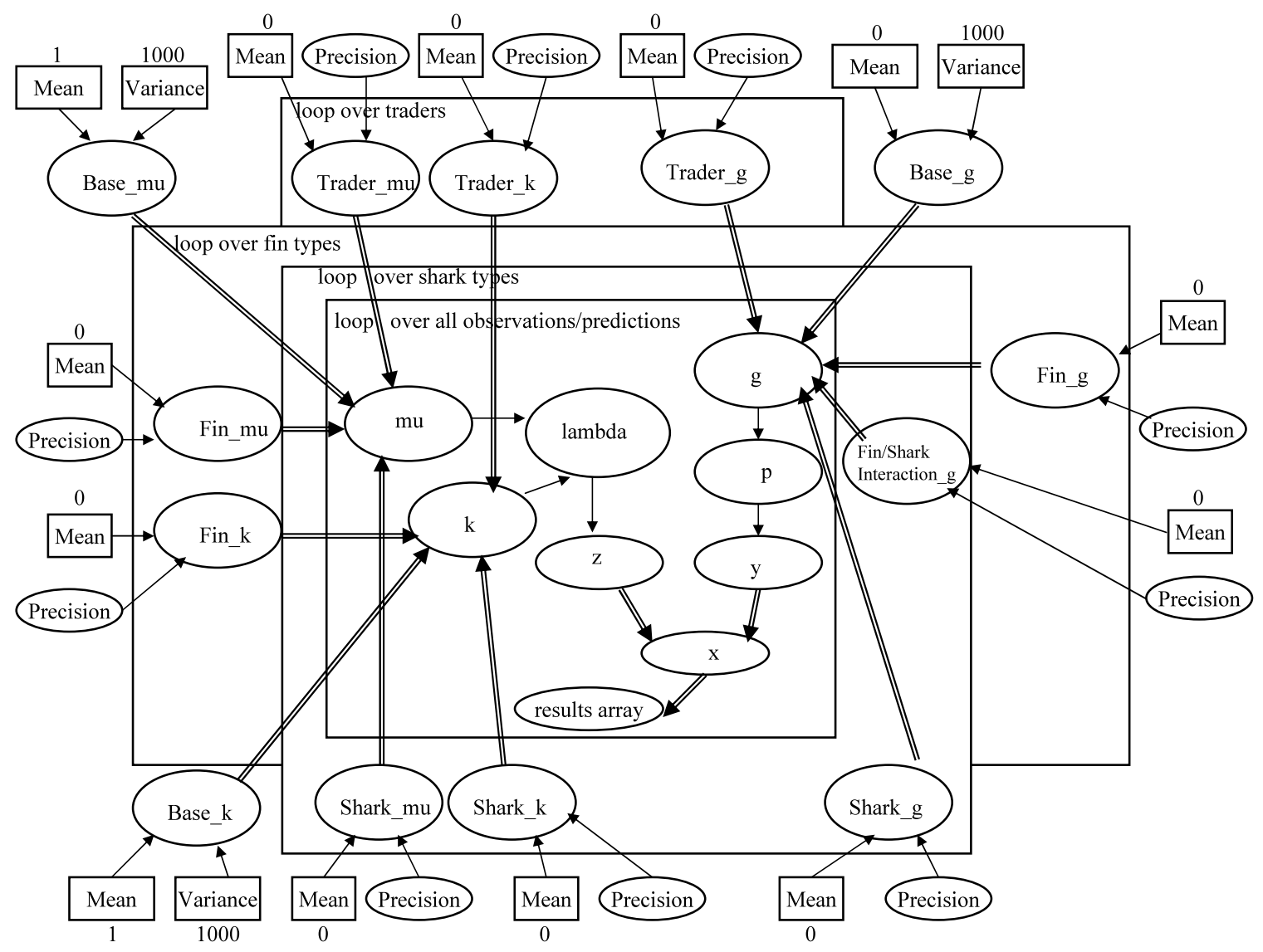

Fig. 5. Flowchart showing derivation and relationships between parameters for Model B. See Fig. 3 caption for explanation of icons. This model uses an alternative formulation of the negative binomial distribution, such that ' $z[i]$ ' is normally distributed with mean 'lambda[i]' and precision 'prec $[i]$ ', with 'prec $[i]$ ' $=1 /$ 'lambda $[i]$ ', and 'lambda $[i]$ ' determined by a gamma distribution with scale ' $k$ ' and shape ' $k / m u[i]$ '. Parameter ' $z[i]$ ', representing traded fin weight, thus takes a negative binomial distribution. Parameter ' $g$ ' determines the probability of observing a zero weight and ' $p$ ' is the logit transformation of ' $g$ '. Parameter ' $p$ ' is used to derive ' $y$ ', a binomial random variable. The product of ' $z$ ' and ' $y$ ', i.e. ' $x$ ', is the observed/predicted traded weight. Priors for mean nodes (rectangles) were assumed normally distributed around zero (for effects) or one (for base ' $m u^{\prime}$, ' $k$ ' and ' $g$ '). Priors for variance nodes (rectangles) were set at 1000 . All random variables for precision (1/variance) were determined using a gamma distribution with scale parameter 0.001 and shape parameter 0.001 ; these precisions priors are not shown on the diagram for simplification purposes.

undertaken to group fin position effects. Results from these initial runs indicated that for the slope parameter the number of effects for shark type could be reduced from 12 to 3 , and the number of effects for fin position could be reduced from 4 to 3 . For the intercept parameter, the number of shark type effects could be reduced from 12 to 4 , but all 4 fin position effects needed to be retained. The full model was then run for the reduced number of effects, i.e. 14 rather than 32 (Table 2).

The appropriateness of grouping and reducing the number of effects for shark type and fin position was evaluated by using the model to predict values for all observed data points $(n=1980)$. Posterior predictive
$P$-values (Gelman et al., 1995) were then calculated to quantify where in the posterior predictive distribution the observed value lies. Those shark types or fin positions with $P$-values of less than 0.05 , indicating a significant underprediction by the model, were re-examined and iteratively re-grouped, if necessary, to minimize the number of low $P$-values across groups. This was to ensure that all shark type-fin position combinations were accurately predicted. Under the final effects groupings, only $2.4 \%$ of the 1 $980 P$-values were $<0.05$ and these groups represented the best compromise between the number of parameters to be estimated and the predictive power of the model. Convergence was evaluated for all slopes, intercepts and effects using several tests provided within the WinBUGS 
TABLE 2. Grouping of trader-, fin-position and shark-type effects for the parameters in Models A and B (see Fig. 3 and 4 for more information on the parameters).

\begin{tabular}{|c|c|c|c|c|}
\hline Model & Parameter & Effect & $\begin{array}{l}\text { Original Number } \\
\text { of Effects }\end{array}$ & $\begin{array}{c}\text { Final Number } \\
\text { of Effects }\end{array}$ \\
\hline \multirow[t]{4}{*}{ A } & \multirow{2}{*}{ 'slope' } & Shark type & 12 & 3 \\
\hline & & $\mathrm{F}$ in position & 4 & 3 \\
\hline & \multirow[t]{2}{*}{ 'intercept' } & Shark type & 12 & 4 \\
\hline & & $\mathrm{F}$ in position & 4 & 4 \\
\hline \multirow[t]{9}{*}{ B } & \multirow[t]{3}{*}{ 'mu' } & Trader type & 16 & 4 \\
\hline & & Shark type & 12 & 4 \\
\hline & & $\mathrm{F}$ in position & 4 & 2 \\
\hline & \multirow[t]{3}{*}{ 'k' } & Trader type & 16 & 3 \\
\hline & & Shark type & 12 & 2 \\
\hline & & $\mathrm{F}$ in position & 4 & 4 \\
\hline & \multirow[t]{3}{*}{ 'g' } & Trader type & 16 & 3 \\
\hline & & Shark type & 12 & 4 \\
\hline & & $\mathrm{F}$ in position & 4 & 2 \\
\hline
\end{tabular}

Convergence Diagnostics and Output Analysis software (CODA).

Due to the log-space estimation in Model A, medians rather than means from each of the 313 predicted distributions (Fig. 6) were used as input to Model B. The use of these medians as point estimates for 313 of the 7104 data points input to Model B tends to narrow the probability distributions resulting from Model B. The use of a unique probability distribution function for each median from Model A would be preferable and will be incorporated in future.

As with Model A, initial runs of Model B were devoted to examining the overlap in the probability intervals for effect terms to discern whether the number of effects to be estimated could be reduced. Model B requires effects to be assigned for two parameters in the negative binomial portion of the model and one parameter in the binomial portion. Results indicated that the original 16 trader effects, 4 fin position effects, and 12 shark type effects could be simplified into a smaller number of effects terms by grouping trader-, fin-position and shark-type without loss of predictive power (Table 2). The interaction term, applied only in the binomial portion of the model, was calculated for each unique combination of shark type-fin position from the reduced number of shark type and fin position groups. Convergence for all effects parameters was evaluated using CODA. In cases where these diagnostics indicated inefficiency or lack of convergence, the grouping of effects terms was re-evaluated to assess whether alternative groups could improve convergence efficiency without sacrificing predictive power. Ultimately, all parameter estimates converged using the limited number of effects shown in Table 2.

Evaluation of posterior predictive p-values showed that $\sim 4 \%$ of the simulated data points significantly underpredicted the actual values. To avoid a downward bias in the final results, the predicted values for all observed data points were summed and compared with the sum of all observed data points. The predicted value sum was $91.338 \%$ of the observed sum and thus a correction factor of 1.095 was applied in the model to every predicted data point prior to the final array summation.

The results of Model B are the mean and its 95\% probability interval for each shark type-fin position combination modeled (Table 3). Each value represents the summation of all observed data, and a number of samples from the predicted data distribution for each combination based on the known number of auctions held and the identity of the trader holding the auction. Nodes were included in the model to iteratively sum the traded fin weights for each shark type (i.e. all fin positions combined within each shark type), and overall, to provide a mean and probability interval for each sum (Table 4). The proportion that each shark type forms of the overall traded shark fin weight was also estimated stochastically (Table 4).

These results indicate that of the individually modeled market categories of shark type, Ya Jian, thought to correspond to blue shark (Prionace glauca) comprises the largest distinct proportion of fins at $18.2 \%$. The next 


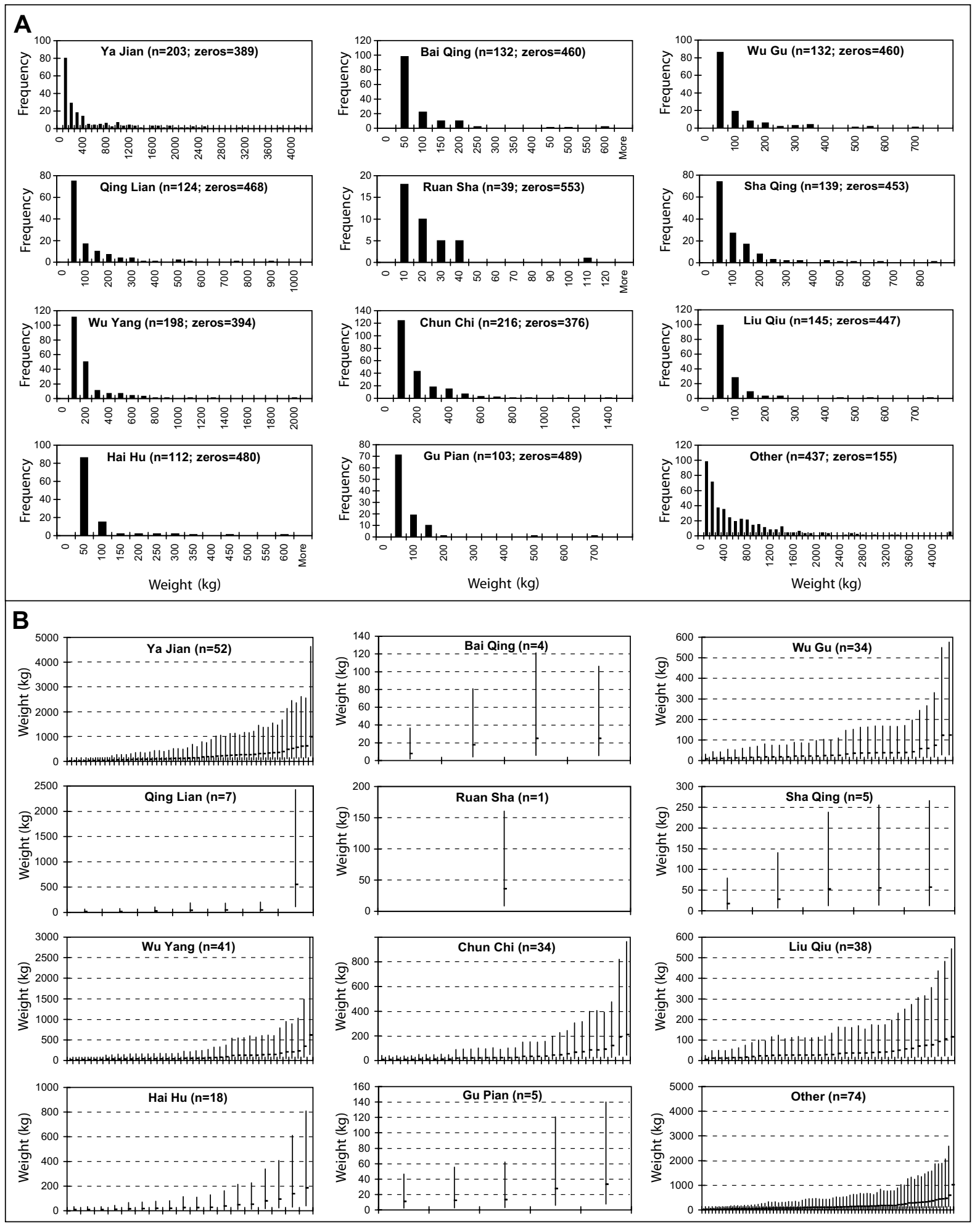

Fig. 6. Total weight-per-auction by shark type (see Table 1 for associated species names) in observed and predicted data sets. Data points for each shark type represent a mixture of all fin positions for presentation purposes only. Fig. 6 (A) shows a histogram (frequency $v s \mathrm{~kg}$ ) of the observed total auction weights for each shark type. Fig. 6 (B) shows the $95 \%$ probability intervals for each of the 313 missing data points produced by Model A for each shark type. For each missing data point, medians are represented by small squares while lines represent the $95 \%$ probability interval. These intervals are shown in ascending order by median in each plot. 
TABLE 3. Estimates of total traded shark fin weight by shark type (traders' nomenclature) and fin position based on Hong Kong auctions held from October 1999 to March 2001. Model output has been divided by 1.5 to express figures on an annual basis.

\begin{tabular}{|c|c|c|c|c|}
\hline \multirow[b]{2}{*}{ Traders' market category } & \multicolumn{4}{|c|}{ Mean weight (95\% probability interval) $(\mathrm{kg})$} \\
\hline & Dorsal Fins & Caudal Fins & Pectoral Fins & Unidentified Fins \\
\hline Ya Jian & $\begin{array}{c}40682 \\
(33820-48383)\end{array}$ & $\begin{array}{c}34126 \\
(27191-42053)\end{array}$ & $\begin{array}{c}137045 \\
(118337-158334)\end{array}$ & $\begin{array}{c}2203 \\
(72-6689)\end{array}$ \\
\hline Qing Lian & $\begin{array}{c}7645 \\
(6254-9140)\end{array}$ & $\begin{array}{c}8282 \\
(6975-9745)\end{array}$ & $\begin{array}{c}21462 \\
(17789-25587)\end{array}$ & $\begin{array}{c}465 \\
(0-1399)\end{array}$ \\
\hline Wu Yang & $\begin{array}{c}9834 \\
(8471-11378)\end{array}$ & $\begin{array}{c}9685 \\
(8306-11241)\end{array}$ & $\begin{array}{c}32050 \\
(28409-36 \quad 122)\end{array}$ & $\begin{array}{c}558 \\
(100-1465)\end{array}$ \\
\hline $\mathrm{Hai} \mathrm{Hu}$ & $\begin{array}{c}4018 \\
(3273-4895)\end{array}$ & $\begin{array}{c}3811 \\
(3035-4713)\end{array}$ & $\begin{array}{c}11846 \\
(9915-14035)\end{array}$ & $\begin{array}{c}346 \\
(104-825)\end{array}$ \\
\hline Bai Qing & $\begin{array}{c}5750 \\
(4657-6995)\end{array}$ & $\begin{array}{c}4431 \\
(3324-5685)\end{array}$ & $\begin{array}{c}11600 \\
(8681-14946)\end{array}$ & $\begin{array}{c}16978 \\
(13184-21293)\end{array}$ \\
\hline Ruan Sha & $\begin{array}{c}376 \\
(225-587)\end{array}$ & $\begin{array}{c}313 \\
(165-527)\end{array}$ & $\begin{array}{c}1036 \\
(634-1599)\end{array}$ & $\begin{array}{c}112 \\
(13-385)\end{array}$ \\
\hline Chun Chi & $\begin{array}{c}6657 \\
(5552-7943)\end{array}$ & $\begin{array}{c}6475 \\
(5403-7774)\end{array}$ & $\begin{array}{c}15640 \\
(12676-19111)\end{array}$ & $\begin{array}{c}25986 \\
(22260-30131)\end{array}$ \\
\hline Gu Pian & $\begin{array}{c}2245 \\
(1685-2907)\end{array}$ & $\begin{array}{c}2134 \\
(1539-2778)\end{array}$ & $\begin{array}{c}6084 \\
(4528-7919)\end{array}$ & $\begin{array}{c}10334 \\
(8298-12749)\end{array}$ \\
\hline $\mathrm{Wu} \mathrm{Gu}$ & $\begin{array}{c}7927 \\
(6576-9402)\end{array}$ & $\begin{array}{c}7697 \\
(6326-9249)\end{array}$ & $\begin{array}{c}20656 \\
(17003-24885)\end{array}$ & $\begin{array}{c}916 \\
(466-1825)\end{array}$ \\
\hline Sha Qing & $\begin{array}{c}5052 \\
(3976-6245)\end{array}$ & $\begin{array}{c}4012 \\
(2913-5233)\end{array}$ & $\begin{array}{c}11910 \\
(8923-15277)\end{array}$ & $\begin{array}{c}19938 \\
(16023-24280)\end{array}$ \\
\hline Liu Qiu & $\begin{array}{c}4766 \\
(4017-5625)\end{array}$ & $\begin{array}{c}4181 \\
(3417-5048)\end{array}$ & $\begin{array}{c}12676 \\
(10580-14946)\end{array}$ & $\begin{array}{c}244 \\
(0-735)\end{array}$ \\
\hline Other & $\begin{array}{c}101645 \\
(92130-112330)\end{array}$ & $\begin{array}{c}95275 \\
(85840-105717)\end{array}$ & $\begin{array}{c}211717 \\
(184300-242198)\end{array}$ & $\begin{array}{c}226837 \\
(198008-258850)\end{array}$ \\
\hline
\end{tabular}

largest proportions were Chun Chi $(4.7 \%)$ comprising at least two species of hammerheads (Sphyrna sp.), and Wu Yang (4.4\%), thought to correspond to silky shark (Carcharhinus falciformis) and other visually similar Carcharhinid fins (see Table 1). Other fins comprised $\sim 54 \%$ of the total traded weight of 1176 tons per year. These included other distinct market categories not included in this study, as well as fins, which may actually belong to one of the eleven modeled-categories but described as unidentified fins on the auction sheets. The probability interval for the total traded weight over a one-year period extends from 1108 to 1247 tons.

\section{Discussion}

The results from the present study can be extrapolated to the entire quantity of shark fins transiting Hong Kong (i.e. including unauctioned fins), and to the global fin trade. Furthermore, these results can be used to estimate the numbers of sharks represented by these traded weights. For interim reference purposes only, we present simplified assumptions, which can be applied to achieve rough approximations of quantities of interest. Estimation of these quantities is currently being implemented in a probabilistic framework. 
TABLE 4. Estimates of total traded shark fin weight by shark type (traders' nomenclature) and overall for Hong Kong auctions held from October 1999 to March 2001. Model output has been divided by 1.5 to express figures on an annual basis. All quantities have been stochastically simulated and thus individual categories may not sum to the total given in the last row.

\begin{tabular}{lrrrr}
\hline \hline $\begin{array}{l}\text { Traders' Market } \\
\text { Category }\end{array}$ & $\begin{array}{r}\text { Mean Traded } \\
\text { Weight (kg) }\end{array}$ & $\begin{array}{c}\text { 95\% Probability Interval } \\
\text { for Mean weight (kg) }\end{array}$ & $\begin{array}{c}\text { Percentage of } \\
\text { Overall Total }\end{array}$ & $\begin{array}{c}\text { 95\% Probability Interval for } \\
\text { Percentage of Overall Total }\end{array}$ \\
\hline Ya Jian & 214096 & $190791-240021$ & 18.21 & $16.58-19.95$ \\
Qing Lian & 37852 & $33465-42900$ & 3.22 & $2.84-3.65$ \\
Wu Yang & 52133 & $47738-57092$ & 4.44 & $4.02-4.89$ \\
Hai Hu & 20023 & $17422-23018$ & 1.70 & $1.47-1.96$ \\
Bai Qing & 38763 & $33304-44634$ & 3.30 & $2.84-3.81$ \\
Ruan Sha & 1837 & $1221-2672$ & 0.16 & $0.10-0.23$ \\
Chun Chi & 54754 & $49149-61043$ & 4.66 & $1.50-2.07$ \\
Gu Pian & 20797 & $17640-24329$ & 1.77 & $2.76-3.60$ \\
Wu Gu & 37191 & $32655-42335$ & 3.16 & $3.02-3.99$ \\
Sha Qing & 40924 & $35433-47012$ & 3.48 & $1.63-2.12$ \\
Liu Qiu & 21865 & $19220-24905$ & 1.86 & $51.77-56.26$ \\
Other & 635836 & $584630-690670$ & 54.06 & NA \\
Total Traded Weight & 1175712 & $1107975-1247480$ & NA & \\
\hline
\end{tabular}

The point estimate of annual auctioned weight of 1176 tons compares with an independent estimate of 5930 tons of fins imported to Hong Kong in 2000. This independent estimate is the reported quantity (Anon., 2001), adjusted for water content of frozen fins and double counting of fins re-imported from Mainland China after thawing (Clarke et al., in press). This suggests that the results presented in Tables 3 and 4 represent $\sim 20 \%$ of the shark fins traded through Hong Kong. If, as believed, Hong Kong controls about half of the world shark fin trade (Clarke, MS 2002), then the modeling undertaken for the present study was performed on a sample of $\sim 10 \%$ of the global market.

These figures assume that a sample drawn from auctioned fins is representative of the shark fin market as a whole. However, it is possible that auctioned fins have a potentially higher value than unauctioned fins, and that is the reason they are offered to the highest bidder on the open market. Hong Kong shark fin traders exhibit a preference for fins which contain longer, thicker and denser fin rays (Fong and Anderson, 2000; Clarke, pers obs); therefore, larger fins of high value species may occur more frequently in the auction dataset. Nevertheless, many very small, poor quality shark fins have been observed at Hong Kong auctions. It is not possible to conclusively address this issue from existing information.

Another concern is the number of sharks represented by traded fin weights. To illustrate the utility of the modeling results, simplified assumptions based on conversion factors from the literature can be applied to the estimates of Ya Jian fins presented in Table 4. Preliminary genetic testing of a small sample of Ya Jian fins from the Hong Kong market $(n=12)$ has confirmed the species identity as blue shark (Prionace glauca) (Shivji et al., 2002). This species is thought to be one of the most abundant and prolific of pelagic sharks (Cortés 2002; Smith et al., 1998). Two conservative assumptions are adopted from a previous study (Clarke and Mosqueira, 2002):

1. Dried fin weight is $2 \%$ of total weight of the shark when landed (Rose, 1996; McCoy and Ishihara, 1999; Anderson and Ahmed, 1993).

2. Small sharks have an average weight of $20 \mathrm{~kg}$ and larger sharks have an average weight of $40 \mathrm{~kg}$ (based on various datasets including Bonfil (MS 1994).

In addition, based on existing information it is assumed that the auction sample from Hong Kong represents $10 \%$ of the global trade (see above). Applying these assumptions to the quantities of Ya Jian fins in Table 4 as follows:

and

$$
\begin{gathered}
\text { low estimate }=(214096 \mathrm{~kg} \text { per year } \times \\
\left.0.02^{-1} \times 10\right) / 40 \mathrm{~kg}
\end{gathered}
$$

$$
\begin{gathered}
\text { high estimate }=(214096 \mathrm{~kg} \text { per year } \times \\
\left.0.02^{-1} \times 10\right) / 20 \mathrm{~kg}
\end{gathered}
$$

indicates that between 2.7 and 5.4 million blue sharks are represented in the shark fin trade each year. 
Because this estimate is based on simplifying assumptions, ongoing research will extend the Bayesian algorithm, both within the existing models and in an additional model calculating the number of sharks represented, for each shark type-fin position combination. One enhancement will involve using probability distributions, rather than point estimates, when transferring the output from Model A to Model B. In addition, another model will be developed (Model C) to convert shark type- and fin position-specific weights in Table 2 into the number of sharks represented. In this model, fin position comparisons between dorsal- and caudal-based estimates, where one fin per shark is contributed, are expected to show a strong similarity. Ideally, these estimates will be, in turn, nearly equivalent to $50 \%$ of the estimates based on pectoral fins, where two fins per shark are contributed.

Existing market databases embody substantial uncertainties, which can be only partially addressed through even the most advanced statistical modeling techniques. Therefore, trade-based assessments of the total take of fishery or wildlife species, such as those described in this paper, are not a substitute for effective monitoring at the point of capture or landing. Although shark catch reporting and independent monitoring requirements are increasing incrementally with time, even in the best managed fisheries they still fall far short of addressing the question of whether vulnerable shark species are being overexploited. For this reason, further development and refinement of trade-based methods should be pursued as an important complement to ongoing and improved future management systems for shark resources. In the short-term, targeting monitoring efforts toward trading centres, particularly when major entrepôts monopolize the flow of the product from numerous locations worldwide, may be the most cost-effective means of gathering a large amount of meaningful data. Obtaining accurate trade data on an ongoing basis will require the cooperation of both governments and business people, which should thus be encouraged with incentives. Working from both the fishery and market ends of the supply chain can provide new insights for management and facilitate the sustainable use of shark resources.

\section{Acknowledgements}

The authors thank Dr Geoff Kirkwood of the Renewable Resources Assessment Group at Imperial College London, Dr Clare Marshall of the Imperial College London Department of Epidemiology and Public Health, and Dr Samu Mäntyniemi of the Finnish Game and Fisheries Research Institute for their helpful suggestions during model development. Dr Tim Hammond, of the Centre for Environment Fisheries and Aquaculture Science-Lowes- toft, kindly provided comments on an early draft of this manuscript. Dr André Punt, School of Aquatic and Fishery Sciences, University of Washington, an anonymous reviewer, and our editor, Dr Terry Walker, made helpful suggestions at a later stage. The pioneering genetics work of Dr Mahmood Shivji and his team at the Guy Harvey Research Institute and Nova Southeastern University is gratefully acknowledged. This research was supported in part by grants from the Wildlife Conservation Society and Imperial College, London.

\section{References}

ANDERSON, R. C., and H. AHMED. 1993. The shark fisheries of the Maldives. Ministry of Fisheries and Agriculture, Republic of the Maldives and Food and Agriculture Organization of the United Nations, $73 \mathrm{p}$.

ANON. 2001. Import, Export and Re-export Statistics by Commodity Code (2000 data). Hong Kong Census and Statistics Department, 19/F Wanchai Tower, Hong Kong Special Administration Region Government, unpubl. data.

BONFIL, R. MS 1994. Overview of world elasmobranch fisheries. Food and Agriculture Organization, Rome, FAO Fish. Tech. Pap., No. 341, 119 p.

CLARKE, S. MS 2002. Trade in dried Asian seafood: characterization, estimation and implications for conservation. Wildlife Conserv. Soc. Work. Pap., No. 22, 88 p.

CLARKE, S. 2003. Quantification of the trade in shark fins. $\mathrm{PhD}$ thesis, Imperial College London, UK, $327 \mathrm{p}$.

CLARKE, S., and I. MOSQUEIRA. 2002. A preliminary assessment of European participation in the shark fin trade. Proc. $4^{\text {th }}$ Europ. Elasm. Assoc. Meet., Livorno (Italy), 2000. M. Vacchi, G. La Mesa, F. Serena, and B. Séret (eds.). ICRAM, ARPAT-GEA \& Soc. Fr. Ichthyol, 2002: 65-72.

CLARKE, S., G. BURGESS, G. CROW, D. A. ROSE, M. SMITH, and C. SIMPFENDORFER. (in press). Socio-economic Importance of Elasmobranchs. In: IUCN Shark Compendium/Status Report, IUCN Shark Specialist Group, 36 Kingfisher Court, Hambridge Road, Newbury, Berkshire, RG14 5SJ, UK.

CORTÉS, E. 2002. Incorporating uncertainty into demographic modeling: application to shark populations and their conservation. Conserv. Biol., 16(4): 1048-1062.

FONG, Q. S. W., and J. L. ANDERSON. 2000. Assessment of the Hong Kong shark fin trade. INFOFISH Inter., 1/2000: 28-32.

2002. International shark fin markets and shark management: an integrated market preference-cohort analysis of the blacktip shark (Carcharhinus limbatus). Ecolog. Econ., 40: 117-130.

GELMAN, A., J. B. CARLIN, H. S. STERN, and D. B. RUBIN. 1995. Hierarchical Models. In: Bayesian Data Analysis. Chapman and Hall, London, p. 119-160.

HILBORN, R., and M. MANGEL. 1997. The ecological detective: confronting models with data. Monographs in Population Biology 28, Princeton University Press, Princeton, New Jersey, 315 p.

KREUZER, R., and R. AHMED. 1978. Shark Utilisation and 
Marketing. Food and Agriculture Organization of the United Nations, Rome, $180 \mathrm{p}$.

MCALLISTER, M. K., and G. P. KIRKWOOD. 1998. Bayesian stock assessment: a review and example application using the logistic model. ICES J. Mar. Sci., 55: 1031-1060.

MCALLISTER, M. K., E. K. PIKITCH, and E. A. BABCOCK. 2001. Using demographic methods to construct Bayesian priors for the intrinsic rate of increase in the Schaefer model and implications for stock rebuilding. Can. J. Fish. Aquat. Sci., 58(9): 1871-1890.

MCCOY, M. A., and H. ISHIHARA. 1999. The socio-economic importance of sharks in the U.S. flag areas of the western and central Pacific (Admin. Rep. AR-SWR-99-01) prepared for U.S. Department of Commerce, National Marine Fisheries Service, Southwest Region, 119 p.

ROSE, D. A. 1996. An overview of world trade in sharks and other cartilaginous fishes, TRAFFIC International, Cambridge, $106 \mathrm{p}$.

PARRY-JONES, R. 1996. TRAFFIC report on shark fisheries and trade in Hong Kong. In: The World Trade in Sharks: A Compendium of TRAFFIC's Regional Studies Volume $1,455 \mathrm{p}$.

PUNT, A., and R. HILBORN. 1997. Fisheries stock assessment and decision analysis: the Bayesian approach. Rev. Fish Biol. Fish., 7: 35-63.

SHIVJI, M., S. CLARKE, M. PANK, L. NATANSON, N. KOHLER, and M. STANHOPE. 2002. Rapid molecular genetic identification of body-parts from six pelagic shark species for conservation, management, and trade-monitoring. Conserv. Biol., 16(4): 1036-1047.

SMITH, S., D. AU, and C. SNOW. 1998. Intrinsic rebound potentials of 26 species of Pacific sharks. Mar. Freshw. Res., 49: 663-678.

TANAKA, S. 1994. East Asian Fin Trade. Shark News, No. 2, p. 6 .

VANNUCCINI, S. MS 1999. Shark utilization, marketing and trade. Food and Agriculture Organization, Rome. FAO Fish. Tech. Pap., No. 389. 
